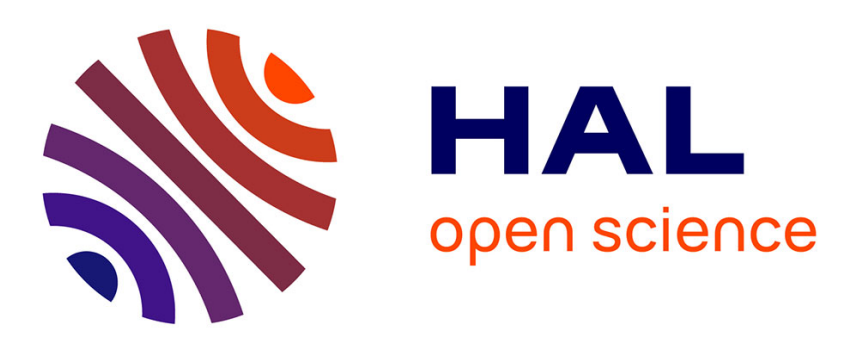

\title{
Imaging endocytic vesicle formation at high spatial and temporal resolutions with the pulsed-pH protocol
}

Silvia Sposini, Morgane Rosendale, Léa Claverie, Thi Nhu Ngoc Van, Damien Jullié, David Perrais

\section{- To cite this version:}

Silvia Sposini, Morgane Rosendale, Léa Claverie, Thi Nhu Ngoc Van, Damien Jullié, et al.. Imaging endocytic vesicle formation at high spatial and temporal resolutions with the pulsed-pH protocol. Nature Protocols, 2020, 15 (9), pp.3088-3104. 10.1038/s41596-020-0371-z . hal-03039165

\section{HAL Id: hal-03039165 https://hal.science/hal-03039165}

Submitted on 3 Dec 2020

HAL is a multi-disciplinary open access archive for the deposit and dissemination of scientific research documents, whether they are published or not. The documents may come from teaching and research institutions in France or abroad, or from public or private research centers.
L'archive ouverte pluridisciplinaire HAL, est destinée au dépôt et à la diffusion de documents scientifiques de niveau recherche, publiés ou non, émanant des établissements d'enseignement et de recherche français ou étrangers, des laboratoires publics ou privés. 
Title: Imaging endocytic vesicle formation at high spatial and temporal resolutions with the pulsedpH protocol

Silvia SPOSINII ${ }^{1,2^{*}}$, Morgane ROSENDALE ${ }^{1,2,3^{*}}$, Léa CLAVERIE ${ }^{1,2,4}$, Thi Nhu Ngoc VAN ${ }^{1,2,5}$, Damien JULLIÉ ${ }^{1,2,6}$ \& David PERRAIS ${ }^{1,2+}$

${ }^{1}$ University of Bordeaux and ${ }^{2}$ CNRS, Interdisciplinary Institute for Neuroscience, UMR 5297, F-33000 Bordeaux, France.

${ }^{3}$ Present address: CNRS, Institut des Sciences Moléculaires, UMR 5255, 33405 Talence, France

${ }^{4}$ Present address: Euroquality, Bordeaux, France

${ }^{5}$ Present address: Sys2diag, Montpellier, France

${ }^{6}$ Present address: University of California, San Francisco, CA 94143 USA

*equal contribution

${ }^{+}$lead author

Correspondence to: David Perrais: david.perrais@u-bordeaux.fr, tel +33 533514861

Interdisciplinary Institute for Neuroscience, CNRS UMR 5297 \& University of Bordeaux, 146 rue Leo Saignat, 33077 Bordeaux, France

EDITORIAL SUMMARY This protocol describes a procedure for live-cell imaging of endocytic events in cultured cells using a $\mathrm{pH}$-sensitive fluorophore and fast extracellular $\mathrm{pH}$ changes. A Matlab-based analysis pipeline is provided to facilitate automated data processing.

TWEET A fully automated protocol for imaging endocytosis in cultured living cells

COVER TEASER Imaging endocytic vesicle scission in cultured living cells

\begin{abstract}
Endocytosis is a fundamental process occurring in all eukaryotic cells. Live cell imaging of endocytosis has helped deciphering many of its mechanisms and regulations. With the pulsed-pH $(\mathrm{ppH})$ protocol, one can detect the formation of individual endocytic vesicles (EVs) with an unmatched temporal resolution of $2 \mathrm{~s}$. EV formation is defined as the moment at which cargo, such as the transferrin receptor (TfR), labeled with a $\mathrm{pH}$ sensitive fluorophore, becomes insensitive to a change in the $\mathrm{pH}$ of the extracellular solution. Fast perfusion enables the complete exchange of extracellular solution around cultured adhering cells every $2 \mathrm{~s}$, defining the temporal resolution of the technique. Unlike other imaging-based endocytosis assays, the $\mathrm{ppH}$ protocol detects EVs without a priori hypotheses on the dynamics of vesicle formation. Here we explain how the $\mathrm{ppH}$ protocol quantifies the endocytic activity of living cells and the recruitment of associated proteins in real time. We provide a step-bystep procedure for expression of the reporter proteins with transient transfection, live cell image
\end{abstract}


acquisition with synchronized $\mathrm{pH}$ changes and automated analysis. The whole protocol can be performed in two days to provide quantitative information on the endocytic process being studied.

\section{Introduction}

\section{Development of the ppH protocol}

Endocytosis, the formation of cytosolic membrane-bound vesicles from the plasma membrane, is an essential feature of eukaryotic cell biology. It has been directly involved in numerous cellular processes such as nutrient uptake, pathogen entry, signal transduction, regulation of plasma membrane receptors and the formation and function of synapses in neurons and immune cells ${ }^{1,2}$. Since the first description of endocytic vesicles containing yolk protein in mosquito oocytes by Roth and Porter ${ }^{3}$, researchers have characterized the endocytosis of a large variety of cargo in many different cell types. An important step in our understanding of endocytosis was that molecularly and structurally distinct types of endocytosis may coexist in a single cell. Besides clathrin-mediated endocytosis (CME), which was first identified and remains the best defined endocytic pathway ${ }^{4}$, several clathrinindependent endocytosis (CIE) pathways have been defined ${ }^{5,6}$. One critical question to understand how endocytosis is organized in cells is to determine the location and dynamics of endocytic sites at the cell surface. To this aim, intense research effort has been dedicated to developing methods that can detect endocytosis events with the highest resolution (reviewed in ${ }^{4,7,8}$ ).

By definition, endocytosis occurs when a cargo (i.e. a ligand or receptor initially on the plasma membrane, or more generally membrane or membrane bound molecules, such as proteins and lipids) is internalized into the cell via endocytic vesicles. Studying endocytosis benefits from several technical advantages over other (intra)cellular membrane trafficking events. First, it takes place at the plasma membrane which is easy to define and visualize. Second, the extracellular environment is easy to access and manipulate, at least for isolated cells or cell monolayers. To distinguish cargo remaining on the cell surface from internalized cargo, researchers have used various methods including cell fractionation, transmission electron microscopy or light microscopy ${ }^{9,10}$. Observation by electron microscopy is the most precise but may be tedious and is only possible on fixed cellular samples. Light microscopy thus appears as a method of choice but, given that endocytic vesicles can have a diameter of $\sim 100 \mathrm{~nm}$, below the limit of resolution of fluorescence microscopy, an endocytic vesicle remaining close to the plasma membrane cannot be distinguished from a cluster remaining on the plasma membrane. To overcome this limitation, researchers have developed alternative methods to visually segregate internalized cargo from the cell surface pool. 
In a typical assay cells are incubated with a specific receptor ligand, an antibody, amine-reactive biotin, a fluid phase or a membrane marker for a defined period of time. The endocytic process is then arrested, for example by putting cells at $4{ }^{\circ} \mathrm{C}$. The marker remaining on the plasma membrane is then specifically removed, 1 ) by simple wash-out because it is intrinsically labile such as the lipid marker FM1-43 $\left.{ }^{11}, 2\right)$ by application of a strong acid buffer $(\mathrm{pH} 3-4)$, which destabilizes most protein-protein interactions, 3) by competition with unlabeled ligand or 4) by the use of reducing agents that can cleave specifically designed markers ${ }^{12}$. Alternatively, the marker can be left on the plasma membrane and detected after chemical fixation thanks to a secondary marker (e.g. an antibody). Finally, the internalized fraction of the endocytic marker can be detected if it is radiolabeled ${ }^{13,14}$ or fluorescent itself, or by a secondary marker after membrane permeabilization (different from the surface secondary marker if applicable). These assays are sensitive and quantitative but they are usable only for a single time point after the initiation of endocytosis and often require cell fixation.

An alternative strategy compatible with live cell imaging is to tag the cargo of interest with fluorophores sensitive to their local environment. One such fluorophore is the fluorescent protein superecliptic pHluorin (SEP), a mutant of the green fluorescent protein (GFP) which is brightly fluorescent at $\mathrm{pH} 7.4$ (i.e. the extracellular $\mathrm{pH}$ ) but not fluorescent at $\mathrm{pH}<6.0^{15,16}$. This latter value corresponds to the $\mathrm{pH}$ of intracellular organelles such as secretory vesicles, recycling endosomes or synaptic vesicles. Therefore, SEP-tagged membrane proteins localized to these organelles have been widely used to study exocytosis by monitoring the $\mathrm{pH}$ change occurring when the cargo is re-exposed to the extracellular environment after exocytosis ${ }^{15-19}$. Because of its sensitivity to $\mathrm{pH}, \mathrm{SEP}$ can also be used to report endocytosis. Effectively, application of extracellular solution with low pH (5.5) monitors the location of a cargo tagged with SEP. If the tag is accessible to the solution exchange, i.e. the cargo is still at the surface, SEP fluorescence will vanish during exposure to low pH buffer. Oppositely, if the tag is trapped inside vesicles, i.e. the cargo has been internalized, SEP will remain fluorescent even during application of low pH solution. For example, in cells transfected with the transferrin receptor (TfR-SEP), a receptor that clusters at clathrin coated pits (CCPs) on the plasma membrane and is constitutively internalized by $\mathrm{CME}$, a subset of clusters resists quenching by the application of low $\mathrm{pH}$ buffer (Fig. 1a). This subset of clusters corresponds to intracellular vesicles with luminal pH above 6.5. By alternating between $\mathrm{pH} 7.4$ and pH 5.5 every $2 \mathrm{~s}$, newly formed endocytic vesicles are revealed as fluorescent spots in images taken at pH 5.5 corresponding to the pre-existing clusters seen at $\mathrm{pH} 7.4$ (Fig. 1b-d). These spots disappear within $\sim 20 \mathrm{~s}$ regardless of the $\mathrm{pH}$ at the surface, as natural acidification of the luminal $\mathrm{pH}$ of vesicles along their maturation occurs soon after endocytosis by vacuolar $\mathrm{H}^{+}$ATPase activity. Using this protocol, the time and location of single endocytic vesicle formation can be precisely determined. We named it the pulsed $\mathrm{pH}$ protocol $(\mathrm{ppH})^{20}$. 
The $\mathrm{ppH}$ protocol was originally developed in $2005^{20}$ and has since then undergone several developments, including a semi-automated analysis which allows to systematically monitor the recruitment of $\mathrm{CME}$-related proteins to forming $\mathrm{CCVs}^{21-23}$. For example, the maximum recruitment of dynamin, a large GTPase which cuts the vesicle neck and is thus essential for vesicle formation ${ }^{24}$, coincides with the time of scission, i.e. 2-4 s before CCV detection (Fig. 1c,d and Fig. 4d) ${ }^{21}$. More recently, we have developed a supervised machine-learning feature for fully automated analysis ${ }^{25}$. In this article, we will describe (1) the imaging setup to acquire time lapse movies of cells transfected with SEP-tagged cargo (TfR) in synchrony with pH changes and (2) the automated analysis to extract quantitative data.

\section{Applications of the $\mathrm{ppH}$ protocol}

The $\mathrm{ppH}$ protocol is based on live cell fluorescence imaging. We mainly use TIRF microscopy but various imaging modalities including simple wide field epifluorescence ${ }^{20}$ and highly inclined and laminated optical sheet microscopy (HiLo) have been tested ${ }^{26}$. Others such as spinning disk and classical confocal microscopy could be employed as we $\|^{27}$. By predominantly illuminating the first $\sim 100$ $\mathrm{nm}$ of the surface of cultured cells adhering to the glass coverslip, TIRF microscopy is indeed particularly suited to observe endocytosis ${ }^{28}$, fusion pore dynamics ${ }^{19}$, early steps of endosome maturation, as well as phago- and pino-cytosis.

Typically, cells are transfected with membrane protein cargo tagged with SEP. Over the years, we have tested various mammalian cell lines (NIH 3T3, HeLa, COS7, BSC1, HEK293) as well as primary cells in culture (neurons, astrocytes) ${ }^{19,26,29}$. Moreover, we have developed the $\mathrm{pH}$ sensitive red fluorescent protein $\mathrm{pHuji}^{30}$ for simultaneous imaging of the endocytosis of two cargo (one labelled with $\mathrm{SEP}$, the other with $\mathrm{pHuji}$ ) into individual $\mathrm{CCVs}^{30,31}$. Another promising marker is the red $\mathrm{pH}$ sensitive organic fluorophore Virginia Orange which can label specific protein domains such as SNAPtag or antibodies $^{32}$ (Table 1). Other pH sensitive dyes, like cypHer ${ }^{33}$ or pHrodo Red dextran ${ }^{34}$, do not have sufficient dynamic range to be used for the $\mathrm{ppH}$ assay. The cargo that we have studied the most is the transferrin receptor (TfR), which is exclusively and constitutively internalized at high rates through $C M E$, but the endocytosis of other membrane proteins has been reported: $\beta 2$ adrenergic receptors ${ }^{29,30}$, GluA1 and GluA2 AMPA-type glutamate receptors ${ }^{29,35}, \mu$ opioid receptor ${ }^{26,31}$ and GPI anchored cargo ${ }^{36}$. One difficulty is that for some receptors, such as AMPA receptors ${ }^{29,37}$, a significant fraction is located in intracellular but only mildly acidic organelles such as the endoplasmic reticulum. These receptors thus resist the extracellular $\mathrm{pH}$ changes and may obscure the detection of endocytic vesicles. To solve this issue, we performed photobleaching while perfusing a low $\mathrm{pH}$ solution prior to imaging ${ }^{29,35}$. At this $\mathrm{pH}$, surface receptors are not fluorescent, hence protected from the photobleaching. 'Background 
fluorescence' having been thus bleached, a clear detection of endocytic events becomes possible during imaging.

Cells can be imaged with TIRF microscopy and the $\mathrm{ppH}$ protocol at a frequency of $0.5 \mathrm{~Hz}$ for at least 40 minutes $22,25,29$. Within this time window, the frequency of recorded endocytic events is constant. Therefore, it is possible to measure the effect of treatments stimulating or inhibiting endocytosis on single cells in a quantitative way. We have verified the innocuousness of the $\mathrm{ppH}$ protocol on endocytosis in a number of ways. First, the frequency of recorded events is constant in all cell types tested (see above). Second, cells are able to internalize the ligand transferrin to the same extent as cells that do not experience the $\mathrm{pH}$ changes ${ }^{20,29}$. Third, the cytoplasm of cells acidifies only minimally ( $0.2 \mathrm{pH}$ units after 15 minutes) during the $\mathrm{ppH}^{20}$. Fourth, the number and degree of CCP invagination, measured with transmission electron microscopy, do not change after treatment with an acidic solution ${ }^{21}$. Fifth, in most cells (with the notable exception of neurons), the application of low $\mathrm{pH}$ solution does not induce any detectable current, measured by whole cell patch-clamp recordings $\mathrm{s}^{25,29,38}$. In neurons, application of low pH solution activates acid-sensing ion channels but these channels can be blocked without influencing the frequency of recorded endocytic events ${ }^{29}$. Alternatively, low $\mathrm{pH}$ solution can be replaced by a green fluorescence quencher, e.g. trypan purple, which allowed us to record a similar number of events as with the original ppH protocol ${ }^{29}$. However, trypan purple slowly accumulates at the surface of cells such that it cannot be used for more than 5 minutes to assess endocytosis activity quantitatively.

Until now, we have used the $\mathrm{ppH}$ protocol on cells overexpressing cargo proteins tagged with fluorescent $\mathrm{pH}$ sensitive proteins, through transient transfection of either cell lines or primary neuronal cultures. The constant progress in genome-editing techniques makes the production of genome-edited cell lines with these tagged receptors very likely very soon. This could lead to high-throughput, quantitative assays of endocytosis in living cells which will be amenable for molecular screens. Moreover, the $\mathrm{ppH}$ protocol is compatible with patch clamp ${ }^{25}$ and we are currently also combining the protocol with super-resolution microscopy such as single particle tracking photoactivation localization microscopy (spt-PALM). The high spatial and temporal precision in localizing newborn endocytic vesicles will make the $\mathrm{ppH}$ protocol a very powerful technique to explore the dynamics of endocytosis at nanoscopic scales.

\section{Comparison with other methods}

In a recent review article $^{8}$ we described the four main families of methods to detect the formation of endocytic vesicles, the last one being the $\mathrm{ppH}$ protocol and its variants. All four families of methods have their own advantages and limitations. In the first family, methods were designed to 
distinguish cargo left on the plasma membrane from internalized cargo, either by transmission electron microscopy or by sequential labelling and permeabilization. However, this requires fixation of the biological sample and is thus not compatible with live cell imaging, which led to the development of the other three families of methods. The second family is based on the monitoring of endosomal acidification following cargo internalization. Like the $\mathrm{ppH}$, it uses a $\mathrm{pH}$ sensitive tag, most often SEP, and follows the overall cellular decrease in fluorescence as endosomes acidify. This method has been very useful to monitor the internalization of synaptic vesicles in neurons where endocytosis is synchronized with exocytosis ${ }^{39}$. However, confounding factors, such as the acidification of the endoplasmic reticulum after treatments which induce receptor endocytosis, can complicate the interpretation of these measures. Moreover, since this method monitors fluorescence at the cellular scale rather than the single vesicle scale, if endocytosis is not triggered by a stimulus (by exocytosis of synaptic vesicles in neurons, or ligand application for some receptors) it cannot be monitored by this method. In addition, it reports on acidification, a process that can be decoupled from endocytosis per se.

The third family of methods measures the turnover of endocytic sites. It has been vastly regarded by the scientific community as the method of choice for studying CME with live cell imaging ${ }^{4,7,27}$. In this case, clathrin itself or associated proteins are specific markers of endocytic sites, i.e. clathrin coated structures (CCSs) such as flat, curved or closed clathrin lattices, at the plasma membrane and report on the various steps of vesicle formation: (i) appearance of CCS and growth, which corresponds to the initial assembly of a cluster, (ii) stable CCS fluorescence, which corresponds to its maturation, and (iii) disappearance, which corresponds to final invagination, scission, movement of the endocytic vesicle and clathrin uncoating $20,21,40,41$. However, it should be noted that the temporal precision of this assay with regards to membrane scission is limited. We showed with the ppH assay that the time of CCS disappearance gives an inaccurate and imprecise estimate of membrane scission, with a temporal uncertainty comparable to the time course of CCS invagination and CCV formation : scission occurs $7 \pm 22$ s before CCS fluorescence decreases by 50\% (mean \pm standard deviation, 107 events in six NIH 3T3 cells ${ }^{21}$ ). Moreover, it relies on a number of assumptions on how an endocytic zone should behave (e.g. CCSs should completely disappear after a CCV is formed). Most importantly, this type of approach cannot be used for other endocytic pathways independent of clathrin ${ }^{42-45}$, where clear markers of endocytic sites are lacking.

Finally, the fourth family comprises the $\mathrm{ppH}$ protocol and its variations. It is based on the simplest operational definition of endocytosis: the transition of a cargo from the plasma membrane to an intracellular vesicle. Thus, it does not rely on any strong assumption like the second and third families of methods. Moreover, its temporal resolution is unparalleled: the moment of scission is defined by the frame rate at which imaging is performed and is only limited by the exchange of 
solution. We typically use $2 \mathrm{~s}$, which is much lower than the process of cargo recruitment and internalization through $\mathrm{CME}$, therefore providing sufficient sampling ${ }^{21}$. Finally, because the endocytic vesicle is detected within the $2 \mathrm{~s}$ of its birth, its location can be determined with very high precision, potentially beyond the limit of diffraction of light microscopy. This is of invaluable help to define hot spots of endocytosis, such as the side of pre $e^{46,47}$ and post-synaptic structures ${ }^{29,48}$ or cell adhesion sites $^{49}$.

\section{Limitations}

The main limitation of the $\mathrm{ppH}$ protocol is the need for a fast perfusion system. We describe here the use of a local perfusion pipette mounted on a micromanipulator, a setup that may not be suited for all microscopy setups. Alternatively, microfluidic channels, which can achieve comparable exchange rates as the one we have set up ${ }^{50,51}$, could be a good alternative. In addition, we show that the exchange rate depends on the accessibility of the plasma membrane of the imaged cell (Fig. 2). In systems in which access to the extracellular space is difficult, such as the basolateral side of epithelia or slices of tissue, fast exchange will not be possible. It should also be noted that because the cell is bathed in low $\mathrm{pH}$ solution half of the time, only the vesicles formed during perfusion at $\mathrm{pH} 7.4$ will be detected. The ones formed during perfusion at $\mathrm{pH} 5.5$, thus already acidic, will remain non fluorescent. Consistent with this prediction, CCS disappearance events, another signature of CCV formation (as explained in Comparison with other methods section), are associated with a TfR-SEP vesicle isolated at pH $5.554 \%$ of the time $(107 / 197 \text { events) })^{21}$. This is also seen as the occasional recruitment of endocytic proteins such as dynamin1-mCherry to CCS without the appearance of a vesicle (Fig. 1c). Nevertheless, this datum indicates that the application of low pH solution does not affect scission. Consequently, the high number of detections makes it possible to study the endocytic process with high temporal and spatial precision as well as with high statistical power.

The effect of the application of low pH solution on endocytosis or other cellular processes could be another limitation of the ppH protocol. We have performed at least five control experiments (see Application of the $\mathrm{ppH}$ protocol above) to demonstrate the lack of effect of the $\mathrm{ppH}$ protocol on general endocytosis. However, specific endocytic pathways could be affected, calling for the need of control experiments in particular systems. For example, activation of NMDA-type glutamate receptors, which in neurons stimulates the internalization of AMPA-type glutamate receptors, is blocked at $\mathrm{pH}$ 5.5. However, this block is fully reversible upon application of solution at $\mathrm{pH} 7.4$ and stimulation of internalization is observed during the $\mathrm{ppH}$ protocol ${ }^{29}$. Finally, if low $\mathrm{pH}$ solution impairs endocytosis of the cargo under investigation, extracellular quenchers such as Trypan purple can be employed instead of low $\mathrm{pH}$ solution ${ }^{29}$. 


\section{Experimental design}

The $\mathrm{ppH}$ protocol is designed for adherent cells in culture. Fast exchange of the extracellular medium is best achieved with a two channel application pipette mounted on a micromanipulator. Therefore, the coverslip with adherent cells is mounted in an open chamber with heated bath perfusion to perform experiments at physiological temperature. The pipette is positioned such that the cell is bathed in either $\mathrm{pH} 7.4$ or pH 5.5 buffer (Fig. 2a). With optimal positioning, fast and reversible exchange of solutions is achieved (see Supplementary Figure 2 for troubleshooting). We monitored the exchange of solution with HeLa cells transfected with TfR-SEP with continuous TIRF imaging at 10 $\mathrm{Hz}$ (Fig. 2b-d). The very large surface of this cell type adhering to the coverslip reveals the time needed to exchange solution underneath the cell. Indeed, the middle of the cell requires more time to exchange, about one second, than its edges (Fig. 2b,c; Supplementary Movie 1). In all six cells tested, the exchange of solution was complete in all parts well before the end of the $2 \mathrm{~s}$ application, making this time interval a conservative estimate of exchange for time lapse recording. On the other hand, in smaller cells or cellular processes such as neurites, solution exchange can be very fast, enabling more precise measurements: with a modified $\mathrm{ppH}$ protocol switching solutions at $2.5 \mathrm{~Hz}$, we could measure fusion pore opening time during dendritic exocytosis, which lasts between 0.2 and $16 \mathrm{~s}$ (median 2.6 s) ${ }^{19}$.

\section{Materials}

Biological Materials

- $\quad$ NIH 3 T3 (ECACC, cat. No. 93061524, RRID:CVCL_0594), BSC1 (ECACC, cat. No. 85011422, RRID:CVCL_0607) or HeLa cells (ECACC, cat. No. 93021013, RRID:CVCL_0030), or any adherent cell type of interest. This protocol has been shown to work in COS7 cells, HEK293T cells ${ }^{31}$, mouse embryonic fibroblasts $(\mathrm{MEFs})^{25}$, dissociated rat and mouse neuron and astrocyte cultures ${ }^{29}$. CAUTION The cell lines used should be regularly checked for mycoplasma infection.

\section{Reagents}

Reagents for cell culture and transfection

- MycoAlert Mycoplasma Detection Kit (Lonza, cat. no. LT07-118)

- Poly-I-lysine (PLL) (Sigma-Aldrich, cat. no. P2636 or specific ligand for adhesion proteins (e.g., fibronectin, laminin) for adherence of cells)

- DMEM 1× w/ sodium pyruvate (Eurobio Scientific cat no. L0106-500) 
- glutamax 100x (Thermo Fisher Scientific, cat. no. 35050038)

- fetal calf serum (Eurobio Scientific cat no. CVFSVF00-01),

- Neurobasal Medium 1× (Thermo Fisher Scientific, cat. no. 12348-017)

- B27 supplement, or equivalent (Thermo Fisher Scientific, cat. no. 17504001)

- Plasmid encoding the protein of interest fused to the $\mathrm{pH}$ sensitive tag (SEP or pHuji), e.g. TfR$\mathrm{SEP}^{20}$ or TfR-pHuji ${ }^{30}$ (Addgene, cat. No. 61505). Optional: mCherry tagged protein of interest (e.g. dynamin1-mCherry, Addgene \# 27697).

CAUTION Care should be taken when choosing the insertion site of the SEP/pHuji tag: it must be exposed to the extracellular environment

- Standard reagents for DNA transfection in mammalian cells (e.g. Fugene 6, Promega cat. no. E2691). Lipofectamine 2000 is another possibility but we noticed that when we combined imaging with patch-clamp ${ }^{25}$ the cells were more fragile than when transfected with Fugene (personal communication). We have also successfully used electroporation of MEF cells with the nucleofector MEF1 kit (Lonza, cat. no. VPD-1004) ${ }^{25}$.

- D-glucose (Sigma-Aldrich, cat. no. G7528-1KG)

- $\mathrm{NaCl}$ (Sigma-Aldrich, cat. no. S7653-1KG)

- $\quad \mathrm{KCl}$ (Sigma-Aldrich, cat. no. P9333-1KG)

- $\mathrm{MgCl}_{2} 6 \mathrm{H}_{2} \mathrm{O}$ (Sigma-Aldrich, cat. no. $\mathrm{M} 2670-100 \mathrm{G}$ )

- $\mathrm{CaCl}_{2} 2 \mathrm{H}_{2} \mathrm{O}$ (Sigma-Aldrich, cat. no. C5080-500G)

- HEPES (Sigma-Aldrich, cat. no. H4034-500G)

- MES monohydrate (Sigma-Aldrich, cat. no. 69892-25G)

- $\mathrm{NaOH}$ (Sigma-Aldrich, cat. no. S8045-500G) CAUTION NaOH is corrosive. Wear protective gloves and clothing.

Reagents for evaluation of the TIRF illumination and two color alignment

- Tetraspeck $^{\mathrm{TM}}$ microspheres, $0.2 \mu \mathrm{m}$ size (Invitrogen cat. no. T7280)

CRITICAL: if the two color images do not need to be aligned, use FluoSpheres ${ }^{\circledR} 0.2 \mu \mathrm{m}$ size, yellow/green (Invitrogen cat. no. F8811). Use a 1/1000 dilution in water.

- Immersion oil, type HF (Cargille cat. no. 16245)

\section{EQUIPMENT}

Equipment for mammalian cell culture and transfection

- Standard equipment for mammalian cell culture

- Sterile 6- and 12-well cell culture plates

- Bottle-top filtration system for buffer sterilization

- 18-mm-diameter glass coverslips (Harvard Apparatus, cat. no. 64-0714)

- Tweezers

- Nucleofector ${ }^{\mathrm{TM}} 2 \mathrm{~b}$ device (Lonza Bioscience) for electroporation, program MEF T20 for MEF cells.

Recording chamber and bath perfusion

- Low profile quick change chamber for $18 \mathrm{~mm}$ coverslips (Warner Instruments RC-41LP) with QE-1 heated quick exchange platform

- Dual channel temperature controller (Warner Instruments TC-344B) with in line solution heater SF-28 
- Peristaltic pump (Gilson MINIPULS 3 Peristaltic Pump (cat. no. F155006)

- Vacuum pump (KNF LABOPORT ${ }^{\mathrm{TM}}$ PPS Pump Head EPDM Mini Diaphragm Vacuum Pump, cat. no. N 86 KN.18)

Local perfusion system for $\mathrm{pH}$ exchange (illustrated in Supplementary Figure 1)

- Vertical glass pipette puller (Narishige)

- Diamond knife

- Plastic and fused silica MicroFill ${ }^{\mathrm{TM}}$ tubing (World Precision Instruments, cat. no. CMF28G50L)

- Fast epoxy glue (Radiospare cat. no. 553-614)

- $1.5 \mathrm{mM}$ Theta glass capillaries (Harvard Apparatus, cat. no. TG150)

- Bench microscope (e.g. World Precision Instruments W30S-LED) equipped with a 5x objective to examine the tip of the application pipette.

- Tubing (Tygon ${ }^{\circledast}$ Saint-Gobain Fluid Transfer cat no. ACF00001-C and ACF00002-C)

- Three-way electrovalves (Lee Company, cat. no. LHDA1233115H)

- Syringes (Becton Dickinson Plastipak Luer Lok, cat. no. 305959)

- Filters, $5 \mu \mathrm{m}$ pore size (Merck Millex-SV cat. no. SLSV025LS)

- Relay card (Velleman K8090 or Arduino Uno) to drive the electrovalves

- Motorized micromanipulator (Sutter cat. no. MP225) to position the perfusion pipette CRITICAL: a manual 3- or 4-axes precision manipulator (e.g. World Precision Instruments cat. no. M3301) should be sufficient for positioning the perfusion pipette and be more cost effective.

TIRF microscope

- Laser source (Cobolt Lasers 06-DPL $473 \mathrm{~nm}, 100 \mathrm{~mW}$ and 06-MLD $561 \mathrm{~nm}, 50 \mathrm{~mW}$ ) assembled in a Laser bench (Gataca Systems)

- Olympus IX71 inverted microscope with TIRF illuminator (IX2-RFAEVA) or Ilas2 illuminator (Gataca Systems)

- Olympus UAPON150XOTIRF objective (1.45 NA, oil immersion) or UPLAPO100XOHR objective (1.49 NA, oil immersion)

- Dichroic mirror Di03-R405/488/561/635, emission filters ET525/50m and ET63)2/60m for GFP and mCherry imaging, respectively, mounted on a TwinCam 2 camera system (Cairn Research) bearing a dichroic mirror (560dclp, Chroma Technology)

- 2 EMCCD cameras (QuantEM Model 512SC, Princeton Instruments)

Software

- Metamorph 7.10 (Molecular Devices) https://www.moleculardevices.com

- Matlab 2018b (Mathworks) https://www.mathworks.com

- "scission_analysis" Matlab toolbox (https://fr.mathworks.com/matlabcentral/fileexchange/72744-scission analysis)

\section{REAGENT SETUP}

Standard culture medium: Standard cell culture medium for mammalian cell culture (DMEM $1 \times$ ) supplemented with $1 \%$ (vol/vol) glutamax and $10 \%$ (vol/vol) fetal calf serum. The medium can be stored for 2 months at $4{ }^{\circ} \mathrm{C}$. 
Neurobasal Medium: Neurobasal Medium 1× supplemented with 10\% (vol/vol) B27 supplement, or equivalent. The medium can be stored for 2 months at $4{ }^{\circ} \mathrm{C}$.

Stock solutions: We normally prepare $1 \mathrm{M}$ stock solutions of $\mathrm{KCl}, \mathrm{MgCl}_{2}$ and $\mathrm{CaCl}_{2}$ for faster preparation of the imaging buffers. The stock solutions can be stored for 6 months at $4{ }^{\circ} \mathrm{C}$.

HBS: Prepare HEPES buffered solution (HBS) for imaging, containing (in $\mathrm{mM}$ ): $135 \mathrm{NaCl}, 5 \mathrm{KCl}, 0.4$ $\mathrm{MgCl}_{2}, 1.8 \mathrm{CaCl}_{2}, 1 \mathrm{D}$-glucose and $20 \mathrm{HEPES}$. Adjust $\mathrm{pH}$ to 7.4 with $\mathrm{NaOH}$ and osmolality to $310-315$ mosm (matching the osmolality of the culture medium) with $\mathrm{NaCl}$ or milliQ ${ }^{\mathrm{TM}}$ water. Filter-sterilize and store at $4^{\circ} \mathrm{C}$ for up to 6 months.

MBS: Prepare MES buffered solution (MBS) for imaging, containing (in $\mathrm{mM}$ ): $135 \mathrm{NaCl}, 5 \mathrm{KCl}, 0.4$ $\mathrm{MgCl}_{2}, 1.8 \mathrm{CaCl}_{2}, 1 \mathrm{D}$-glucose and $20 \mathrm{MES}$. Adjust $\mathrm{pH}$ to 5.5 with $\mathrm{NaOH}$ and osmolality to 310-315 mosm (matching the osmolality of the culture medium) with $\mathrm{NaCl}$ or milliQ ${ }^{\mathrm{TM}}$ water. Filter-sterilize and store at $4^{\circ} \mathrm{C}$ for up to 6 months.

\section{EQUIPMENT SETUP}

\section{Application pipette}

1. Pull one theta glass capillary to a minimal section size of about $400 \mu \mathrm{m}$ in one step. Let the glass cool down. Indent the side of the glass at its narrowest with a diamond knife. The capillary will break by gravity under the weights of the puller, creating two pipettes. Check the tip of the glass pipette with the benchtop microscope. A clean flat break will ensure the fastest exchange between the two solutions (Fig. 2a). If not satisfactory, pull other theta glass capillaries.

2. Cut pieces of MicroFill tubes of about $3 \mathrm{~cm}$ long. Insert one in each channel at the back of the theta pipette for about $1 \mathrm{~cm}$.

3. Prepare epoxy resin by mixing the two components.

CAUTION! Epoxy resin is harmful in contact to skin or inhaled. Use appropriate protection.

4. Use a drop of resin to fix the MicroFill tubes to the back of the pipette. Make sure the resin seals the back without clogging the channels. Let it dry and harden.

Application pipettes can be prepared months in advance. If well maintained (thoroughly rinsed with water after each experimental session), not broken or clogged, one pipette can be used for several months.

\section{Perfusion}

Assemble a perfusion line per solution (HBS and MBS) composed of a syringe, a filter ( $5 \mu \mathrm{m}$ pore size), a stopcock, a connector for $0.8 \mathrm{~mm}$ ID tubing and tube to connect to the 3-way electrovalves. If the experiment involves application of a compound, add two additional lines with the compound dissolved in HBS and MBS, respectively. We recommend keeping the tubing diameters and length identical between lines to ensure optimal transitions between control and treatment. We recommend to have separated set of tubes for each compound to avoid cross-contamination.

Put an application pipette on the pipette holder and connect it with tubing to the electrovalves. The application pipette can stay on the holder between experiments.

\section{PROCEDURE}




\section{Plating and transfection of cells}

TIMING 2 days, 1 hour hands-on time.

CRITICAL this protocol describes the live imaging of TfR-SEP endocytosis in NIH 3 T3 cells. Adapt the protocol to other cell types or reporter proteins if necessary.

1. Maintain cell lines in a T25 flask with appropriate culture medium in a humidified incubator at $37^{\circ} \mathrm{C}$ and $5 \% \mathrm{CO}_{2}$. To passage, pre-warm PBS, trypsin, and culture medium to $37^{\circ} \mathrm{C}$. Remove the culture medium, rinse the T25 flask with $5 \mathrm{ml} \mathrm{PBS}$, add $0.5 \mathrm{ml}$ trypsin and incubate the cells at $37{ }^{\circ} \mathrm{C}$ until the cells have detached (typically 1-5 minutes). After the cells have detached, add $8 \mathrm{ml}$ full medium and resuspend the cells thoroughly to obtain a single cell suspension. Split the cells two times a week at a 1:20 ratio.

2. For transfection, seed the cells one day before in a T25 flask. Transfect the cells at $50-60 \%$ confluence with $1.5 \mu \mathrm{g}$ TfR-SEP plasmid DNA using $6 \mu$ l Fugene 6 following manufacturer's protocol. If co-transfection with mCherry tagged protein, decrease the amount to $1 \mu \mathrm{g}$ of TfRSEP plasmid and add $0.5 \mu \mathrm{g}$ of the mCherry plasmid.

CRITICALSTEP It is critical to achieve a high transfection efficiency without inducing cell toxicity or too high overexpression. Adjust the amount of DNA and Fugene 6 when necessary. Other transfection reagents such as lipofectamine 2000 or JetPrime, as well as electroporation (e.g. with Lonza Nucleofector ${ }^{\mathrm{TM}}$ ) might also be used according to manufacturer's protocol.

3. 6 to $24 \mathrm{~h}$ after transfection, harvest the cells as in Step 1 and seed them on glass coverslips (18 $\mathrm{mm}$ round \#1 borosilicate) in 12 -well plates. It is important that cells are seeded at low density (10-20\% confluence) to allow imaging of individual cells the following day.

\section{Preparation of the imaging setup}

Timing 1 hour, 30 minutes hands on time

4. Warm up HBS and MBS solutions to $37^{\circ} \mathrm{C}$.

5. Prime the perfusion lines with the pre-warmed solutions by pushing with the syringe plunger up and down until no bubbles remain in the perfusion lines.

CRITICAL STEP Do not prime the perfusion tubes with cold solutions because gas bubbles will form as solutions reach room temperature, preventing optimal flow.

CRITICALSTEP Priming usually consumes $5-10 \mathrm{ml}$ of solution. If using expensive reagents, prime the perfusion lines with HBS/MBS only and refill with the reagent containing solutions.

6. Connect the perfusion lines to inputs of the 3-way electrovalves. If using two sets of perfusion lines connect the two HBS lines to the two inputs of the same 3-way electrovalve and the two MBS lines to the two inputs of the other electrovalve. Therefore, during the exchange of solution, the $\mathrm{pH}$ of the solution will remain constant (pH 7.4 for HBS and 5.5 for MBS). Refill the syringes when necessary. Make sure the level of solution is the same for all lines. In general, verify that the flow of solution (measured as the frequency of drops) is the same for all lines. Typically we get a flow of 5-6 ml.h-1 per line, for a total of $10-12 \mathrm{ml}^{-\mathrm{h}^{-1}}$, or about $3 \mu \mathrm{l} . \mathrm{s}^{-}$ 1 .

7. Connect the output tubes to the application pipette and finish priming the application system. Make sure that no bubbles remain and rinse thoroughly with control solutions.

8. Turn on the Laser line(s) ( $473 \mathrm{~nm}$ for SEP/GFP and 561 for mCherry/dsRed), the microscope system and camera(s) (QuantEM Model 512SC Imaging Camera, Princeton).

9. Start the imaging software (e.g. Metamorph ${ }^{\circledR}$ ).

10. Turn on the chamber heating system (e.g. Warner Instruments QE-1 heated platform) and let it equilibrate to $37^{\circ} \mathrm{C}$ for about 10 minutes. 
11. Mount a dry coverslip in the recording chamber and put it on the microscope stage with a drop of immersion oil on the objective.

12. Put a drop (1-2 $\mu \mathrm{l}$ ) of solution containing fluorescent beads (either FluoSpheres for single color imaging or TetraSpeck for multicolor imaging). Verify the centering of the illumination. In a correctly aligned system for TIRF illumination, the beads should appear brightly fluorescent when immobilized on the coverslip or blinking as they transiently come close to the coverslip and enter the evanescent field (Supplementary Movie 2). If beads are in pure water, very few beads will adhere to the coverslip.

CRITICAL STEP Proceed quickly as the drop of solution may dry, causing the formation of bead aggregates.

TROUBLESHOOTING

13. Add an equal volume of ionic solution (e.g. HBS) to the drop of beads solution. This will cause the adherence of many beads to the coverslip. Take an image of these beads. For multicolor imaging, take an image with all filter sets corresponding to the imaged colors. We perform simultaneous dual color imaging with either one camera and a Dual-View beam splitter (BioVision) or two cameras with a TwinCam adaptor (Cairn Research). These devices need to be aligned but it is very hard to reach sub-pixel alignment over the whole image. This image in both channels will thus be used prior to image analysis to calculate a space transform to correct one channel relative to the other (see Step 29 for description of the procedure).

14. Turn on the bath perfusion pump (e.g. peristaltic pump) and heating (e.g. Warner Instruments cat. no. SF-28). We typically use a flow of $2 \mathrm{ml} \cdot \mathrm{min}^{-1}$ which is about 10 times bigger than the flow of solution coming from the application pipette (see Step 6). Therefore, the possible mixing of solution far away from the application pipette should lead to only a very slight acidification of the medium.

15. Rinse the bath perfusion with distilled water and prime with HBS. The coverslip used to image the beads can be left on the microscope stage while priming of the chamber perfusion system. Excess solution is removed with a vacuum pump.

16. Stop the bath perfusion pump and remove the coverslip. The setup is now ready for imaging.

\section{Cell imaging}

Timing: less than $1 \mathrm{~h}$

17. With the help of tweezers, take a coverslip from the 12-well plate (from Step 3 ) in the incubator and place it in a $3 \mathrm{~cm}$ petri dish with warm HBS.

18. Gently wipe the coverslip underneath with tissue paper and mount in the imaging chamber. Add warm HBS and place the chamber on the heated platform on the microscope stage.

19. Focus on the coverslip. Start the focus control system (e.g. ZDC on Olympus microscopes). Select a transfected cell for imaging. In the cell lines we have studied, TfR-SEP normally has a punctuate staining with faint diffuse staining outside of puncta (Fig. 1a and 2b). If the expression is too high, the staining is bright and homogenous. If the expression is too low, CCSs can be observed with no diffuse fluorescence at the membrane but CCVs will be hard to detect. TROUBLESHOOTING

20. Move the application pipette tip to the center of the field of view using the micromanipulator. Because high NA objectives for high resolution TIRF imaging have a short working distance (less than $150 \mu \mathrm{m}$ ), initial positioning above the cell is easier with a Bertrand lens located before the eyepieces. Then, remove the lens and place the pipette for optimal positioning (Fig. 2a). With a $100 x$ or $150 x$ objective, this optimal positioning is achieved when the tip of the application pipette is placed slightly out of the field of view, $\sim 200 \mu \mathrm{m}$ away from the cell in all 
three axes. This positioning requires trial and error to be identified (with the help of step 22; Supplementary Figure 2).

21. Open the stopcocks.

22. Start a time lapse recording. We typically use $100 \mathrm{~ms}$ exposure time every $2 \mathrm{~s}$. Depending on the experiment, the recording lasts from 5 to 40 minutes (150 to 1200 frames). pH changes are synchronized with image acquisition (Fig. $2 \mathrm{~d}$ ) such that odd frames are taken are at $\mathrm{pH} 7.4$ and even frames at $\mathrm{pH}$ 5.5. Examine the first frames of the recording: there should be a clear difference in fluorescence at the two different $\mathrm{pH}$ values (Supplementary Figure 3 ). In cells expressing TfR-SEP, the overall fluorescence at $\mathrm{pH} 7.4$ is much higher than that at $\mathrm{pH}$ 5.5. The fluorescence at $\mathrm{pH} 7.4$ should be the same as with no application (i.e. complete exchange between the solutions).

TROUBLESHOOTING

23. Record several cells on the same coverslip in succession. We advise to keep one coverslip in HBS under the microscope for less than $1 \mathrm{~h}$ in total. Moreover, if reagents are applied such as blockers or agonists through the application, only one cell per coverslip should be recorded.

24. At the end of the imaging session, rinse the setup and all perfusion lines thoroughly with water and blow dry using plungers.

\section{Image analysis}

Timing: $15 \mathrm{~min} /$ cell for automated analysis

CRITICAL: We provide an example of a fully analyzed dataset consisting of a NIH 3T3 cell co-transfected with TfR-SEP and dynamin1-mCherry and imaged with simultaneous 2 color TIRF at $0.5 \mathrm{~Hz}$ using the $\mathrm{ppH}$ protocol for 6 minutes (180 frames). The data analysis process is illustrated in Fig. 3. (event detection) and Fig. 4 (quantification). We describe here the main steps for analysis and troubleshooting. We provide a full manual (Supplementary Manual) along with the Matlab ${ }^{\circledR}$ toolbox available for download (https://fr.mathworks.com/matlabcentral/fileexchange/72744scission analysis). See Supplementary Table 1 for a description of all the example data files included in Supplementary Data 1.

25. Load the acquired data in the appropriate analysis software. We have designed a full analysis suite to be run in Matlab ${ }^{\circledR} 2018$ as a toolbox named scission_analysis. It can work with stk files generated by Metamorph ${ }^{\circledR}$ or multiple planes tif files (e.g. 092-1.stk or 092-1.tif from Supplementary Data 1). For other file formats, please use a converter.

26. Create one folder for each cell recorded because of the large number of files generated by the analysis (see Supplementary Table 1).

27. Type 'scission_analysis' in the Matlab command line. A window appears with 23 buttons organized in 12 steps (lines), as shown in Fig. 4a.

28. Click on 'Cut raw movie' to split the 2 color movie into images at the two $\mathrm{pH}$, generating 4 files (e.g. 092-1_TfR5.stk, 092-1_TfR7.stk, 092-1_dyn5.stk and 092-1_dyn7.stk for images of receptor at pH 5.5 and 7.4 and of dynamin at pH 5.5 and 7.4, respectively). These 4 files can be visualized as Supplementary Movies 3, 4, 5 and 6, respectively. A merge of the first two can be visualized as Supplementary Movie 7 . Alternatively, click on ' $1 c^{\prime}$ ' to split a 1 color movie without co-transfection, generating two files at two $\mathrm{pH}$ values (e.g. 092-1_TfR5.stk and 0921_TfR7.stk).

29. OPTIONAL Play the movies with the 'Play' button to make sure the exchange of solution is correct throughout the recording. At this stage, appearance of vesicles (i.e. spots appearing suddenly in the TfR5 movie) should be evident.

TROUBLESHOOTING 
30. OPTIONAL In the case of 2 color movies, correct image registration with an image of beads in two colors (obtained the day of the experiment as in step 12: beads_date.tif), or two images of the beads in the two colors. Use 'Align bead images' to generate a set of coefficients to correct the coordinates of the red channel.

31. Click on 'Segment and track' to segment and track objects in the TfR5 movie. Start with the default parameters and adapt to the recording conditions if needed. Do the same for the TfR7 movie. This step will generate 092-1_TfR5seg.stk and 092-1_TfR7seg.stk, movies of the segmented images (using a threshold of a B-spline wavelet transform), and 092-1_TfR5.trc and 092-1_TfR7.trc, coordinates of the tracked objects in the two movies. Each tracked object receives a unique ID number that will be kept in all subsequent steps.

32. Click on 'Cleanup' to select bona fide scission events with additional criteria for vesicle formation (minimal signal/noise, presence of a preexisting cluster in the TfR7 movie, maximum slope of fluorescence change after vesicle detection). This generates 092-1_cln5.trc (here 5 represents the number of frames skipped before the first event is considered, not the $\mathrm{pH}$ ). Save the 092-1_events.xlsx file which contains all the parameters and the candidate and rejected events. Save the 092-1_thresholds5.fig file which shows the distribution of parameters used for selection: slope, signal/noise and cluster fraction. Rejected events are in blue, candidate events are in red.

33. OPTIONAL Review the selected events with 'Browse Events'. Validate or discard events to generate 092-1_clnR5.trc

34. OPTIONAL Use a SVM to automatically select bona fide scission events, as defined by an operator (i.e. reviewed and confirmed in step 28), generating 092-1_clnSVM5.trc. See full manual to see how to train the SVM.

35. OPTIONAL Click on 'Sort events' to choose events in a specific area of the field of view that has been recorded (e.g. on particular cell if more than one cell has been recorded or a specific part of a cell such as the lamellipodia, etc.).

36. Click on 'Freq' to quantify the cumulative number of events (092-1_freq.fig) and the histogram of frequency per minute (092-1_histo.fig).

37. OPTIONAL Click on 'Freq/mask' to obtain the frequency per $\mu \mathrm{m}^{2}$.

38. OPTIONAL Click on 'min frame' to select events occurring after frame 21 for quantification of fluorescence 20 frames ( $80 \mathrm{~s}$ ) before and after scission, generating 092-1_clnSVM20.trc.

39. Click on 'Quantify fluo' to quantify fluorescence of events in a given channel, generating 0921_TfR5.fig, 092-1_TfR7.fig (graphs displayed in Fig. 4d), 092-1_dyn5.fig and 092-1_dyn7.fig, as well as 092-1_events.xlsx which stores all parameters and measures.

40. Click on 'Interleave and correct red' to generate red fluorescence values corrected for fluorescence bleedthrough from the green to the red channel. It minimizes the sum of squared differences between values at $\mathrm{pH} 7.4$ and 5.5 with a bleedthrough coefficient, shown in 0921_bleedthrough.fig. We obtain values of $3-4 \%$ on our imaging setups.

OPTIONAL Obtain the timing of peak red fluorescence recruitment for individual events and generate a histogram of peak recruitment (Fig. 4e, 092-1_peaks.fig).

41. Click on 'Classify term / non term' to sort events into terminal (TfR7 fluorescence decreases to background values, i.e. CCS disappears) and non-terminal events (CCS does not disappear).

42. Click on 'Randomize' to generate $95 \%$ confidence intervals for fluorescence measurements (stored in 092-1_rand(200).xlsx). 


\section{TIMING}

Steps 1-3, Plating and transfection of cells: 2 days, 1 hour hands-on time.

Steps 4-16, Preparation of the imaging setup: 1 hour, 30 minutes hands on time

Steps 17-24, Cell imaging: less than $1 \mathrm{~h}$

Steps 25-42, Image analysis: $15 \mathrm{~min} /$ cell for automated analysis

\section{Troubleshooting}

Troubleshooting guidance can be found in Table 2 .

Table 2: Troubleshooting Table

\begin{tabular}{|c|c|c|c|}
\hline Step & Problem & Possible reason & Solution \\
\hline 12 & $\begin{array}{l}\text { The Illumination is not } \\
\text { centered }\end{array}$ & $\begin{array}{l}\text { The TIRF Illuminator is } \\
\text { not properly aligned }\end{array}$ & $\begin{array}{l}\text { Align the TIRF illuminator using } \\
\text { manufacturer's procedure }\end{array}$ \\
\hline \multirow[t]{4}{*}{19} & $\begin{array}{l}\text { No transfected cell } \\
\text { can be found }\end{array}$ & $\begin{array}{l}\text { Transfection efficiency } \\
\text { is too low }\end{array}$ & $\begin{array}{l}\text { Use a different transfection } \\
\text { protocol/reagent that is suitable } \\
\text { for the cell line of interest }\end{array}$ \\
\hline & & $\begin{array}{l}\text { The TIRF illumination } \\
\text { is not properly aligned }\end{array}$ & $\begin{array}{l}\text { Realign the illumination using } \\
\text { fluorescent beads }\end{array}$ \\
\hline & & $\begin{array}{l}\text { There is a bubble in } \\
\text { the objective } \\
\text { immersion oil }\end{array}$ & $\begin{array}{l}\text { Remove the coverslip. Wipe off oil } \\
\text { from coverslip and objective. Add a } \\
\text { fresh drop of oil and put the } \\
\text { chamber back onto the objective. }\end{array}$ \\
\hline & & $\begin{array}{l}\text { The MBS perfusion is } \\
\text { open, bath at } \mathrm{pH} 5.5 \\
\text { quenches cellular } \\
\text { fluorescence }\end{array}$ & Close the MBS perfusion line \\
\hline \multirow[t]{4}{*}{ 20-21 } & $\begin{array}{l}\text { No good exchange of } \\
\text { solution (partial } \\
\text { change or no change } \\
\text { at all) }\end{array}$ & $\begin{array}{l}\text { The tip of the pipette } \\
\text { is not placed properly }\end{array}$ & $\begin{array}{l}\text { Move the tip of the pipette for } \\
\text { optimal application }\end{array}$ \\
\hline & & $\begin{array}{l}\text { There is a bubble in } \\
\text { one of the lines, } \\
\text { especially in the } \\
\text { application pipette }\end{array}$ & $\begin{array}{l}\text { Lift the application pipette (to } \\
\text { avoid blowing away the cell) and } \\
\text { push in one (all) line(s) with the } \\
\text { syringe plunger(s) to remove } \\
\text { bubbles }\end{array}$ \\
\hline & & $\begin{array}{l}\text { One of the lines is } \\
\text { clogged at the pipette } \\
\text { tip }\end{array}$ & $\begin{array}{l}\text { Examine the tip of the application } \\
\text { pipette under the microscope. If } \\
\text { the tip is clogged, try removing it } \\
\text { by aspiration. If not successful, } \\
\text { change application pipette }\end{array}$ \\
\hline & & $\begin{array}{l}\text { The flow of the } \\
\text { solution is too low }\end{array}$ & $\begin{array}{l}\text { Increase the flow of the solution by } \\
\text { raising the syringes }\end{array}$ \\
\hline $20-21$ & $\begin{array}{l}\text { The cells react to the } \\
\text { flow of the solution, } \\
\text { e.g. by extending }\end{array}$ & $\begin{array}{l}\text { The flow of the } \\
\text { solution is too strong }\end{array}$ & $\begin{array}{l}\text { Reduce the flow of the solution by } \\
\text { lowering the syringes }\end{array}$ \\
\hline
\end{tabular}




\begin{tabular}{|c|c|c|c|}
\hline & $\begin{array}{l}\text { filopodia towards the } \\
\text { flow }\end{array}$ & & \\
\hline \multirow[t]{2}{*}{28} & $\begin{array}{l}\text { No scission event is } \\
\text { detected }\end{array}$ & $\begin{array}{l}\text { The level of expression } \\
\text { is too low }\end{array}$ & $\begin{array}{l}\text { Record cells with higher expression } \\
\text { level }\end{array}$ \\
\hline & & $\begin{array}{l}\text { Level of fluorescence } \\
\text { at pH } 5.5 \text { is very high. }\end{array}$ & $\begin{array}{l}\text { Try to record cells with lower } \\
\text { expression levels. Alternatively, } \\
\text { photobleach at pH } 5.5 \text { to lower the } \\
\text { background for detecting endocytic } \\
\text { vesicles }\end{array}$ \\
\hline
\end{tabular}

\section{Anticipated results}

The $\mathrm{ppH}$ protocol enables the quantitative measure of endocytic activity in living cells. In cell lines expressing TfR-SEP, several scission events are detected every frame (see Fig. 4c). We routinely use perfusion buffers with ${ }^{20,21}$ or without serum ${ }^{25,30}$ and we did not find any significant difference in the internalization of TfR-SEP. Nevertheless, the internalization of other cargo or clathrin independent endocytosis pathways could be affected by the presence of serum so care should be taken in choosing the imaging buffer. Thanks to the high temporal resolution of the $\mathrm{ppH}$ protocol, fast changes in endocytic activity can be observed, such as ligand-induced internalization of $\beta 2$ adrenergic receptor ${ }^{30,31}$ or the block of endocytosis by GTPyS or peptides dialyzed into a cell by a patch-clamp pipette ${ }^{25}$. Moreover, the high number of events detected in a few minutes of recording and with automated analysis by the scission_analysis suite makes it possible to quickly assess the recruitment of proteins associated with the formation of endocytic vesicles, as shown for dynamin1 in a single cell (Fig. 4) and for about 40 proteins involved in CME with 5-7 cells per protein tested ${ }^{21,23}$.

\section{Data availability statement}

The example data used to generate Figure 4 is available as Supplementary Data 1.

\section{Code availability statement}

The Matlab programs that are used to analyze the $\mathrm{ppH}$ data are written for Matlab2018a with the following Matlab toolboxes: Image Processing, Wavelet, Statistics and Machine Learning and formatted as a toolbox, scission_analysis, available at Matlab Central File Exchange as 72744scission_analysis (...). 


\section{Competing interests}

The authors declare that they have no competing financial interests.

\section{Author contributions}

D.P. designed the experiments. All authors performed many experiments which led to this version of the protocol. D.P. wrote most of the analysis software, with contributions from M.R. and D.J. D.P. and S.S. wrote the manuscript and all authors edited it.

\section{Acknowledgements}

This article is dedicated to Christien James Merrifield (1972-2017) who was instrumental in the development of the ppH protocol. The authors thank Arnaud Rodriguez (Bordeaux Neurocampus) for taking photographs of the imaging and perfusion setup. This work was supported by the Centre National de la Recherche Scientifique (Interface program), the Fondation Recherche Médicale (FRM ING20101221208), the Agence Nationale pour la Recherche (CaPeBIE ANR-12-BSV5-005 and LocalEndoProbes ANR-17-CE16-0012) to D.P., the FRM, a pre-doctoral fellowship from the University of Bordeaux to M.R. and Labex BRAIN fellowships to M.R. and L.C.

\section{RELATED LINKS}

- Key references using this protocolTaylor MJ, et al. (2011). PloS Biology 9(3):e1000604. https://journals.plos.org/plosbiology/article?id=10.1371/journal.pbio.1000604

- $\quad$ Rosendale M, et al. (2017). Cell Reports, 18:1840-1847. https://www.sciencedirect.com/science/article/pii/S2211124717301663

- Rosendale M, et al. (2019). Nature Communications 10:4462. https://www.nature.com/articles/s41467-019-12434-9 
Table 1: characteristics of the $\mathrm{pH}$ sensitive fluorophores suitable for the $\mathrm{ppH}$ assay

\begin{tabular}{|c|c|c|c|c|c|}
\hline Protein & $\mathrm{p} K_{\mathrm{a}}$ & $\mathrm{n}_{\mathrm{H}}$ & $\begin{array}{l}\text { Fluorescence } \\
\text { fold change } \\
\text { (pH 5.5-7.5) }\end{array}$ & $\begin{array}{l}\text { Excitation peak } \\
\text { at } \mathrm{pH} 7.2(\mathrm{~nm})\end{array}$ & $\begin{array}{c}\text { Emission peak at } \\
\text { pH } 7.2(\mathrm{~nm})\end{array}$ \\
\hline SE-pHluorin & 7.2 & 1.90 & 50 & 495 & 512 \\
\hline pHuji & 7.7 & 1.10 & 22 & 566 & 598 \\
\hline pHoran4 & 7.5 & 0.92 & 17 & 547 & 561 \\
\hline Organic dye & & & & & \\
\hline
\end{tabular}

Virginia Orange

$6.7 \quad 1.50$

36

555

581 
a

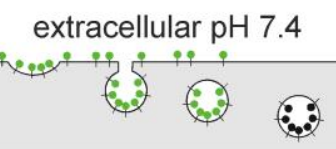

extracellular $\mathrm{pH} 5.5$

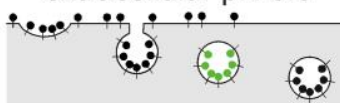

b

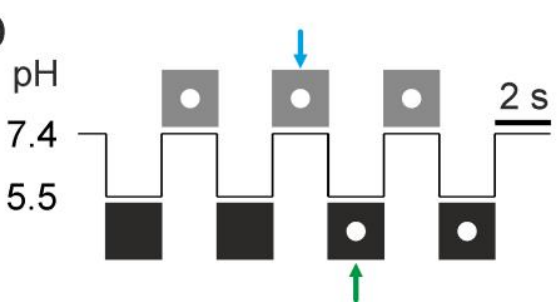

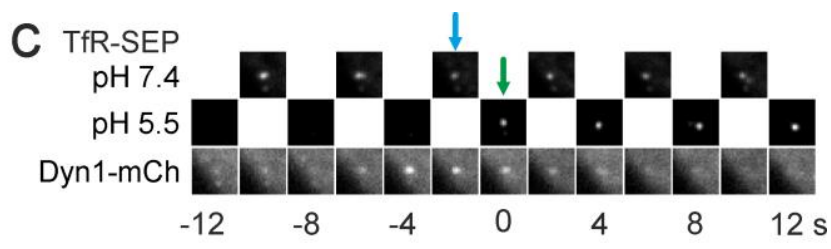

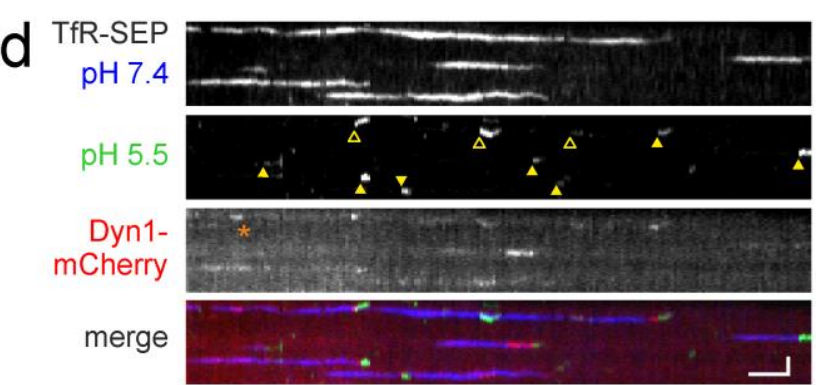

Figure 1: Detection of the formation of endocytic vesicles by the ppH protocol. (a) Experimental procedure. A cell expressing TfR-SEP is bathed in solutions alternating between $\mathrm{pH} 7.4$ and 5.5. At pH 7.4, TfR-SEP on the plasma membrane and in non-acidic vesicles are visible (green lollipops). At pH 5.5, the surface receptors are not fluorescent (black lollipops) and the fluorescence from non-acidic clathrin coated vesicles (CCV) is isolated. (b) Principle of vesicle detection: a CCV formed at pH 7.4 (blue arrow) will be visible on the next image at pH 5.5 (green arrow). (c) Example of a CCV detected at time 0 (green arrow) in an NIH 3T3 cell transfected with TfR-SEP and Dynamin1-mCherry. Note the peak accumulation of dyn 1 at time $-2 \mathrm{~s}$, the moment of vesicle formation (blue arrow). Image size $2.5 \times 2.5$ $\mu m$. (d) Kymographs of an NIH 3T3 cell transfected with TfR-SEP and dyn1-mCherry submitted to the $\mathrm{ppH}$ protocol show CCSs appearing and disappearing (TfR-SEP, pH 7.4). These CCSs produce CCVs towards the end of their life (yellow filled arrowheads) but also during longer lived CCSs (open arrowheads). The accumulation of dyn1-mCherry is observed before the appearance of each CCV. Dyn1 recruitment is also observed without an associated CCV (orange star), perhaps when a vesicle is formed during an acidic pH interval. Scale bars $1 \mu \mathrm{m}$ and $1 \mathrm{~min}$. Panel $\mathrm{c}$ is adapted from Rosendale \& Perrais $2017^{8}$ 
a

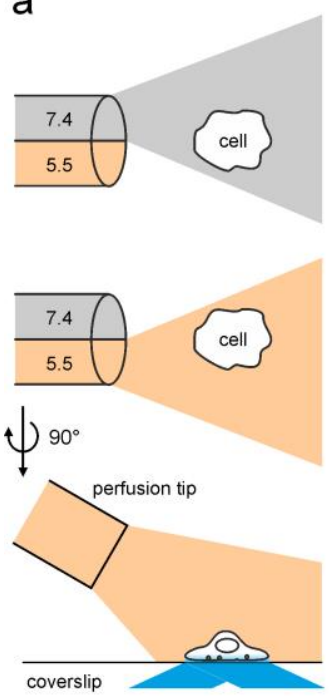

$\mathrm{b}$

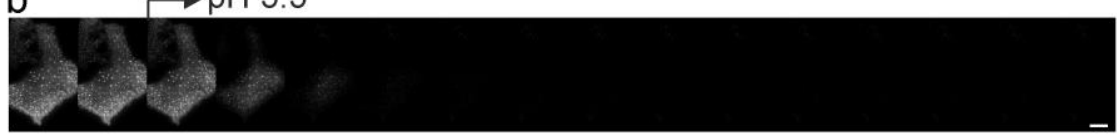

$\longrightarrow \mathrm{pH} 7.4$

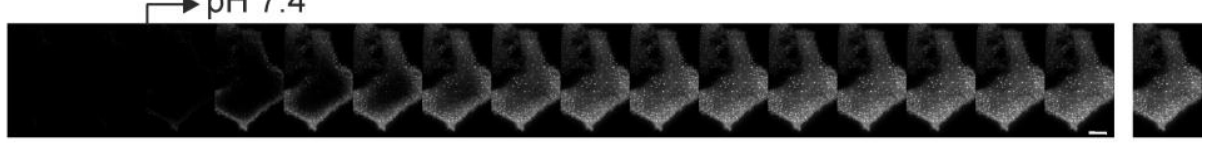

C

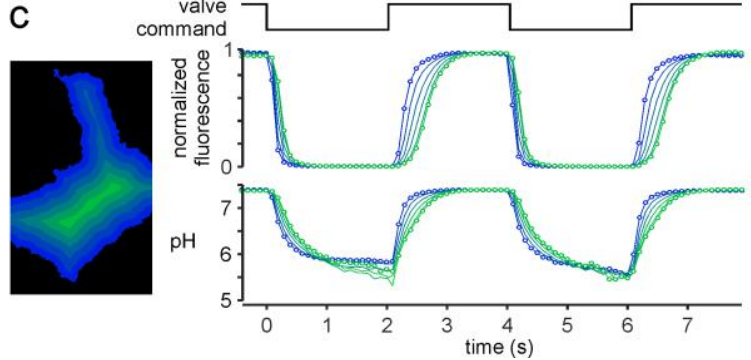

Figure 2: Exchange of solutions underneath the cell monitored with fluorescence imaging. (a) Optimal positioning of the application pipette for fast solution exchange. The septum of the theta application pipette (left) is aligned with the center of the imaged cell. The opening of the valve connected to the $\mathrm{pH} 7.4$ line let the solution flow (grey) while the $\mathrm{pH} 5.5$ is closed (fawn) and vice versa. Bottom, side view showing the position of the pipette relative to the imaged cell. (b) Consecutive frames of a HeLa cell transfected with TfR-SEP imaged at $10 \mathrm{~Hz}$ after switching the buffers from $\mathrm{pH} 7.4$ to 5.5 and vice versa. The fluorescence drops within a few frames. Note that the exchange is faster on the edge of cell than in the middle. Right, image of the cell at the end of the $2 \mathrm{~s}$ application of $\mathrm{pH} 5.5$ buffer at $8 x$ increased contrast with many visible EVs. Scale bar $10 \mu \mathrm{m}$. (c) Plot of normalized fluorescence in portions of the cell in (b) at varying distances from the edge in $2 \mu \mathrm{m}$ steps with color coding depicted in the image on the left. The closer the region is from the edge, the faster the exchange of solution. Note that the drop in fluorescence (7.4 -> 5.5) is faster than the increase (5.5 -> 7.4), presumably because SEP fluorescence varies more around its $\mathrm{pK}_{\mathrm{a}}$. Indeed, conversion of fluorescence values to $\mathrm{pH}$ values with the $\mathrm{pH}$ sensitivity of SEP (bottom traces) using the equation (1) shows similar kinetics for both exchanges.

$$
p H=p K_{a}-\frac{1}{n_{H}} \log \left(\frac{1}{\alpha F}-1\right)
$$

With $\mathrm{F}$, normalized cell fluorescence, $\mathrm{pK}_{\mathrm{a}}=7.2, \mathrm{n}_{\mathrm{H}}=1.9^{30}$ and $\alpha=0.706$, a normalization factor representing SEP fluorescence at $\mathrm{pH} 7.4$ over maximal fluorescence $(\mathrm{pH}>9)$. (d) Diagram of the sequence of images. Image acquisition (100-200 ms exposure) is performed at the end of the application of a given $\mathrm{pH}$. When an EV is detected at time 0 , it corresponds to scission that has occurred when $\mathrm{pH}$ was close to $7.4,2$ to $4 \mathrm{~s}$ before detection (blue area). 
a

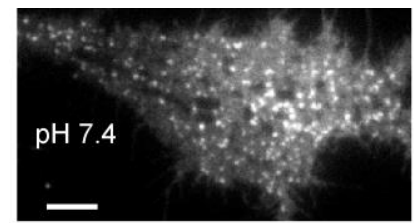

C

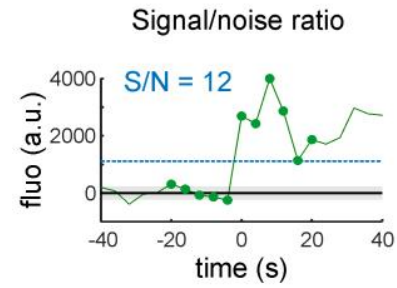

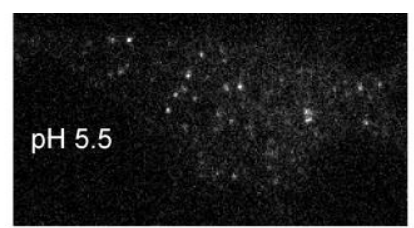

Pre-existing cluster overlap $=0.79$

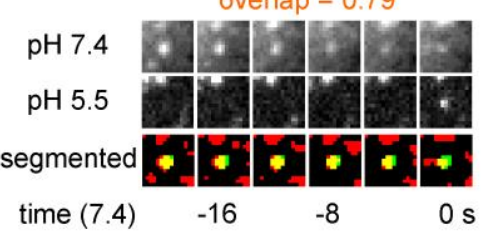

b

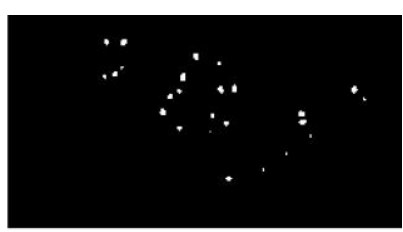

Candiate events

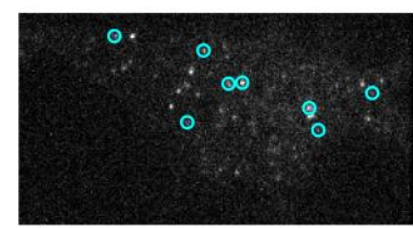

REJECTED d

VALIDATED

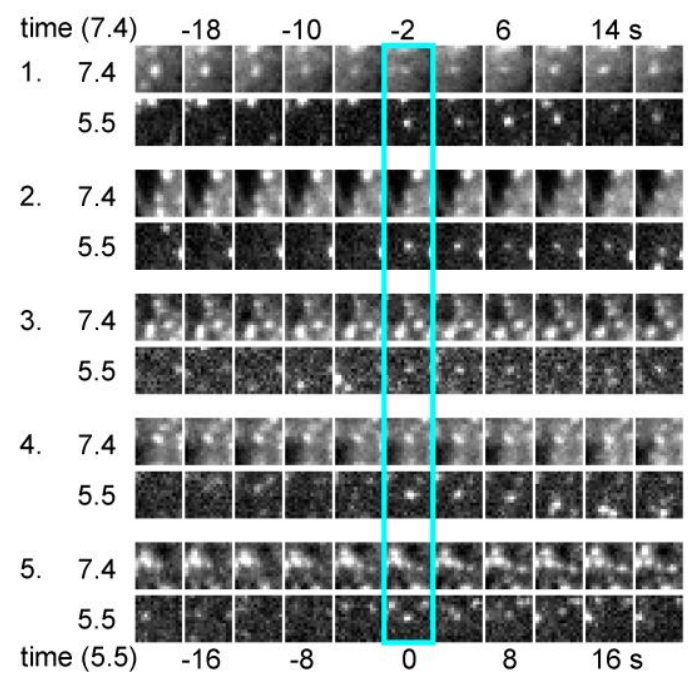

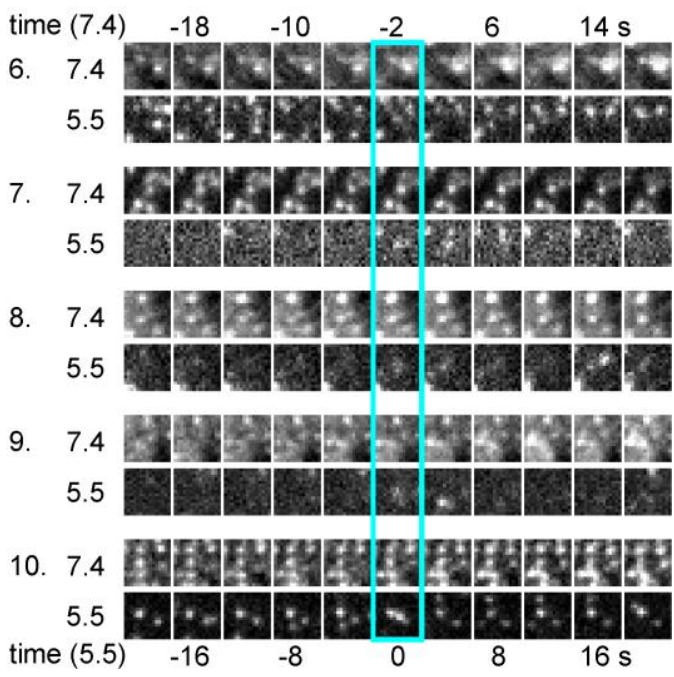

Figure 3: Workflow of automated analysis of ppH data. The four steps (a-d) leading to the characterization of scission events. (a) Acquisition of images at alternate $\mathrm{pH}$ of a $3 \mathrm{~T} 3$ cell transfected with TfR-SEP. Two consecutive images are shown. The image at pH 5.5 is shown with $8 x$ increased brightness than the one at $\mathrm{pH}$ 7.4. Scale bar $5 \mu \mathrm{m}$. (b) Segmentation and tracking of clusters visible at pH 5.5 on the image shown in a. (c) Selection of candidate events based on two criteria. Signal/noise ratio. The average fluorescence in a circle of 2 pixels radius centered on the center of mass of the segmented object is plotted for each frame before and at the start of segmentation (time 0 ). The noise is estimated as the average \pm std before detection (black line, average; gray shading, std). An event is qualified as candidate if the fluorescence at detection divided by the noise estimate $(S / N)$ is bigger than 5. The example (corresponding to event $\mathrm{i}$. in panel $\mathrm{d}$ ) has $\mathrm{S} / \mathrm{N}=12.0$. Image size $1.5 \times 1.5 \mu \mathrm{m}$. Preexisting cluster at $\mathrm{pH}$ 7.4. In segmented images, the location of the event (green) is compared to the clusters of TfR visible at $\mathrm{pH} 7.4$ (red) for the five frames preceding the event. The fraction of green pixels overlapping with red (appearing in yellow) gives an estimate of the colocalization of the candidate vesicle with a parent cluster. An event is qualified as candidate when this fraction is greater than 0.2. For the displayed example (event $\mathrm{i}$. in Panel $\mathrm{d}$ ) the fraction overlap is 0.79 . The cyan circles mark the clusters segmented in b which passed the criteria and correspond to candidate events. (d) Final event validation by a human operator or the trained SVM. Left, gallery of events which were validated by a human operator. In all cases (1-5) the acid resistant spot (vesicle) is clearly visible and can be tracked. Right, gallery of events which were selected by the first screen described in $\mathrm{c}$ but subsequently rejected by a human operator. In cases 6,9 and 10 the acid resistant spot cannot be tracked consistently and in cases 7 and 8 it is barely above background. The choices made for validation and rejection, together with 9621 others in 26 cells, have served to train the SVM. Image sizes $1.5 \times 1.5$ $\mu \mathrm{m}$. Figure adapted from Rosendale et al $2019^{25}$ with permission. 


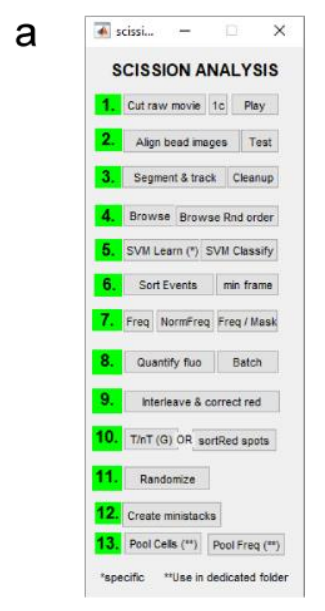

b

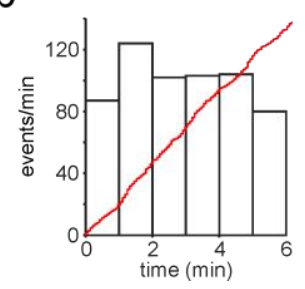

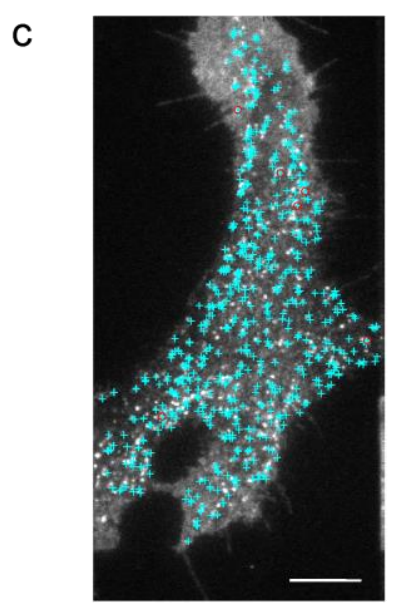

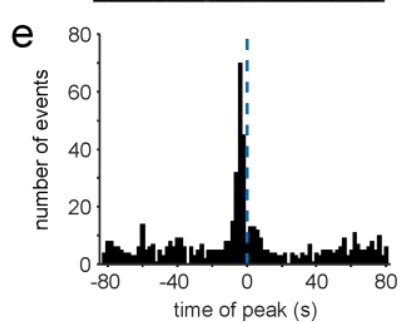

d
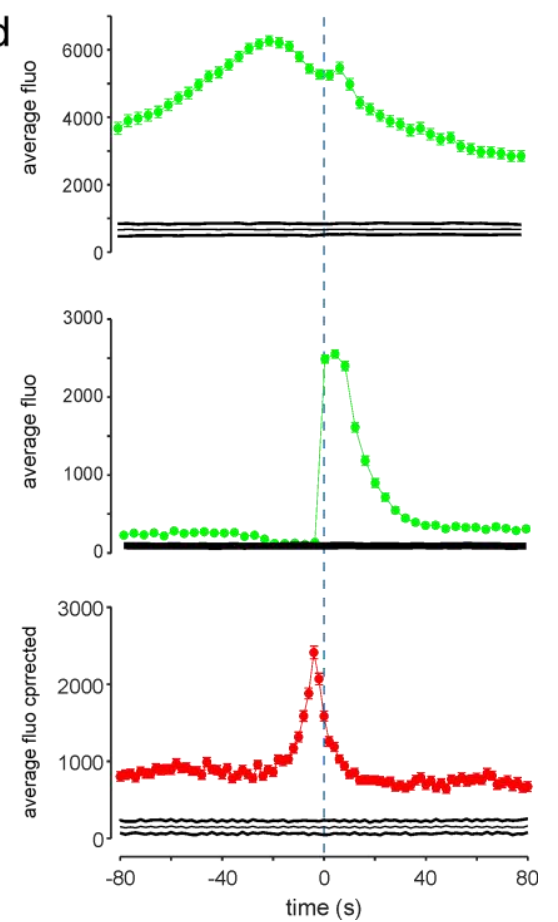

Figure 4: Quantification of endocytic activity with scission_analysis. (a) Front panel of the 'scission_analysis' Matlab program showing functions used for automated analysis. See steps 24-41 and the Supplementary Manual for details. (b-d). Example of a fully analyzed recording in a 3T3 cell transfected with TfR-SEP and dynamin1-mCherry (cell 092-1). (b) Number of events per minute during the recording lasting 6 minutes (180 frames). There are overall 600 events occurring at a frequency of 0.08 events $\cdot \mathrm{min}^{-1} \cdot \mu \mathrm{m}^{-2}$. The red line shows the cumulative number of events over time. (c) Map of the 600 events (cyan crosses) overlaid with the frame 40 of the 092-1_TfR7.stk file as shown with 'play' (line 1. Right button of (a)) with the event file 092-1_clnSVMstart.trc and the 'Show all' option. Events occur in all parts of the cell except in lamellipodia devoid of CCSs (clusters of TfR-SEP). Note the red circles showing the 6 events detected at frame 40. Scale bar $5 \mu \mathrm{m}$. (d) Averaged fluorescence intensity of the 512 events occurring after frame 21, quantified $80 \mathrm{~s}$ before and after vesicle detection, time 0 ). Average \pm SEM of TfR-SEP fluorescence (green circles) at pH 7.4 (top) or 5.5 (middle) and dyn1-mCherry at both $\mathrm{pH}$ (red circles, bottom). Dyn1-mCherry fluorescence is corrected for bleedthrough of the GFP channel with a coefficient of $4 \%$, as determined by 'interleave and correct red' (line 9 of scission_analysis). Note that dyn1-mCh peaks at $-4 \mathrm{~s}$, the time estimated of vesicle formation (see Fig. $2 \mathrm{~d}$ ). The black lines indicate $95 \%$ confidence intervals for significant recruitment as determined by the randomization of data by 200 random shifts within the cell mask ('randomize' line 11). These 512 events are subdivided in 232 'non terminal', 223 'terminal' and 57 'undecided' events. The criteria for subdivision is that TfR7 fluorescence $36-48 \mathrm{~s}$ (9-12 frames) after scission is greater than $60 \%$ for nonterminal (smaller than $40 \%$ for terminal) of its value $12-0$ s before scission. (e) Histogram of the time of peak dyn1-mCherry fluorescence for individual events relative to vesicle formation, time 0. 


\section{References}

1. Sigismund, S. et al. Endocytosis and Signaling: Cell Logistics Shape the Eukaryotic Cell Plan. Physiological Reviews 92, 273-366 (2012).

2. Thottacherry, J. J., Sathe, M., Prabhakara, C. \& Mayor, S. Spoiled for Choice: Diverse Endocytic Pathways Function at the Cell Surface. Annu. Rev. Cell Dev. Biol. 35, 55-84 (2019).

3. Roth, T. F. \& Porter, K. R. Yolk protein uptake in the oocyte of the mosquito Aedes Aegypti L. J. Cell Biol. 20, 313-332 (1964).

4. Kaksonen, M. \& Roux, A. Mechanisms of clathrin-mediated endocytosis. Nature Reviews Molecular Cell Biology 19, 313-326 (2018).

5. Johannes, L., Parton, R. G., Bassereau, P. \& Mayor, S. Building endocytic pits without clathrin. Nature Reviews Molecular Cell Biology (2015).

6. Watanabe, S. \& Boucrot, E. Fast and ultrafast endocytosis. Current Opinion in Cell Biology 47, 6471 (2017).

7. Haucke, V. \& Kozlov, M. M. Membrane remodeling in clathrin-mediated endocytosis. J Cell Sci 131, jcs216812 (2018).

8. Rosendale, M. \& Perrais, D. Imaging in focus: Imaging the dynamics of endocytosis. The International Journal of Biochemistry \& Cell Biology 93, 41-45 (2017).

9. Robinson, M. S. Forty Years of Clathrin-coated Vesicles. Traffic 16, 1210-1238 (2015).

10. Anderson, R. G. W., Brown, M. S. \& Goldstein, J. L. Role of the coated endocytic vesicle in the uptake of receptor-bound low density lipoprotein in human fibroblasts. Cell 10, 351-364 (1977).

11. Betz, W., Mao, F. \& Bewick, G. Activity-dependent fluorescent staining and destaining of living vertebrate motor nerve terminals. The Journal of Neuroscience 12, 363-375 (1992).

12. Bitsikas, V., Corrêa, I. R. \& Nichols, B. J. Clathrin-independent pathways do not contribute significantly to endocytic flux. eLife 3, e03970 (2014).

13. Hopkins, C. R. \& Trowbridge, I. S. Internalization and processing of transferrin and the transferrin receptor in human carcinoma A431 cells. J Cell Biol 97, 508-521 (1983).

14. Lamb, J. E., Ray, F., Ward, J. H., Kushner, J. P. \& Kaplan, J. Internalization and subcellular localization of transferrin and transferrin receptors in HeLa cells. J. Biol. Chem. 258, 8751-8758 (1983).

15. Miesenböck, G., De Angelis, D. A. \& Rothman, J. E. Visualizing secretion and synaptic transmission with pH-sensitive green fluorescent proteins. Nature 394, 192-195 (1998).

16. Sankaranarayanan, S., De Angelis, D., Rothman, J. E. \& Ryan, T. A. The use of pHluorins for optical measurements of presynaptic activity. Biophysical journal 79, 2199-2208 (2000).

17. Yudowski, G. A. et al. Real-Time Imaging of Discrete Exocytic Events Mediating Surface Delivery of AMPA Receptors. Journal of Neuroscience 27, 11112-11121 (2007).

18. Balaji, J. \& Ryan, T. A. Single-vesicle imaging reveals that synaptic vesicle exocytosis and endocytosis are coupled by a single stochastic mode. Proceedings of the National Academy of Sciences 104, 20576-20581 (2007).

19. Jullié, D., Choquet, D. \& Perrais, D. Recycling Endosomes Undergo Rapid Closure of a Fusion Pore on Exocytosis in Neuronal Dendrites. Journal of Neuroscience 34, 11106-11118 (2014).

20. Merrifield, C. J., Perrais, D. \& Zenisek, D. Coupling between Clathrin-Coated-Pit Invagination, Cortactin Recruitment, and Membrane Scission Observed in Live Cells. Cell 121, 593-606 (2005).

21. Taylor, M. J., Perrais, D. \& Merrifield, C. J. A High Precision Survey of the Molecular Dynamics of Mammalian Clathrin-Mediated Endocytosis. PLoS Biology 9, e1000604 (2011). 
22. Taylor, M. J., Lampe, M. \& Merrifield, C. J. A Feedback Loop between Dynamin and Actin Recruitment during Clathrin-Mediated Endocytosis. PLoS Biology 10, e1001302 (2012).

23. Cauvin, C. et al. Rab35 GTPase Triggers Switch-like Recruitment of the Lowe Syndrome Lipid Phosphatase OCRL on Newborn Endosomes. Curr. Biol. 26, 120-128 (2016).

24. Antonny, B. et al. Membrane fission by dynamin: what we know and what we need to know. The EMBO Journal e201694613 (2016) doi:10.15252/embj.201694613.

25. Rosendale, M. et al. Functional recruitment of dynamin requires multimeric interactions for efficient endocytosis. Nat Commun 10, 4462 (2019).

26. Jullié, D. et al. A Discrete Presynaptic Vesicle Cycle for Neuromodulator Receptors. Neuron (2019) doi:10.1016/j.neuron.2019.11.016.

27. Kirchhausen, T. Imaging endocytic clathrin structures in living cells. Trends in Cell Biology 19, 596-605 (2009).

28. Mattheyses, A. L., Simon, S. M. \& Rappoport, J. Z. Imaging with total internal reflection fluorescence microscopy for the cell biologist. J Cell Sci 123, 3621-3628 (2010).

29. Rosendale, M., Jullié, D., Choquet, D. \& Perrais, D. Spatial and Temporal Regulation of Receptor Endocytosis in Neuronal Dendrites Revealed by Imaging of Single Vesicle Formation. Cell Reports 18, 1840-1847 (2017).

30. Shen, Y., Rosendale, M., Campbell, R. E. \& Perrais, D. pHuji, a pH-sensitive red fluorescent protein for imaging of exo- and endocytosis. The Journal of Cell Biology 207, 419-432 (2014).

31. Lampe, M., Pierre, F., Al-Sabah, S., Krasel, C. \& Merrifield, C. J. Dual single-scission event analysis of constitutive transferrin receptor (TfR) endocytosis and ligand-triggered $\beta 2$-adrenergic receptor ( $\beta 2 A R$ ) or Mu-opioid receptor (MOR) endocytosis. Molecular biology of the cell 25, 3070-3080 (2014).

32. Martineau, M. et al. Semisynthetic fluorescent $\mathrm{pH}$ sensors for imaging exocytosis and endocytosis. Nature Communications 8, 1412 (2017).

33. Hua, Y. et al. A readily retrievable pool of synaptic vesicles. Nat. Neurosci. 14, 833-839 (2011).

34. Chen, M., Van Hook, M. J., Zenisek, D. \& Thoreson, W. B. Properties of Ribbon and Non-Ribbon Release from Rod Photoreceptors Revealed by Visualizing Individual Synaptic Vesicles. Journal of Neuroscience 33, 2071-2086 (2013).

35. Fujii, S., Tanaka, H. \& Hirano, T. Detection and characterization of individual endocytosis of AMPA-type glutamate receptor around postsynaptic membrane. Genes to Cells 22, 583-590 (2017).

36. Sathe, M. et al. Small GTPases and BAR domain proteins regulate branched actin polymerisation for clathrin and dynamin-independent endocytosis. Nature Communications 9, 1835 (2018).

37. Rathje, M. et al. AMPA receptor pHluorin-GluA2 reports NMDA receptor-induced intracellular acidification in hippocampal neurons. Proc. Natl. Acad. Sci. U.S.A. 110, 14426-14431 (2013).

38. Perrais, D., Kleppe, I. C., Taraska, J. W. \& Almers, W. Recapture after exocytosis causes differential retention of protein in granules of bovine chromaffin cells. J. Physiol. (Lond.) 560, 413-428 (2004).

39. Kavalali, E. T. \& Jorgensen, E. M. Visualizing presynaptic function. Nature Neuroscience 17, 10-16 (2013).

40. Saffarian, S., Cocucci, E. \& Kirchhausen, T. Distinct Dynamics of Endocytic Clathrin-Coated Pits and Coated Plaques. PLoS Biology 7, e1000191 (2009).

41. Mettlen, M., Loerke, D., Yarar, D., Danuser, G. \& Schmid, S. L. Cargo- and adaptor-specific mechanisms regulate clathrin-mediated endocytosis. The Journal of Cell Biology 188, 919-933 (2010). 
42. Caldieri, G. et al. Reticulon 3-dependent ER-PM contact sites control EGFR nonclathrin endocytosis. Science 356, 617-624 (2017).

43. Boucrot, E. et al. Endophilin marks and controls a clathrin-independent endocytic pathway. Nature 517, 460-465 (2015).

44. Lakshminarayan, R. et al. Galectin-3 drives glycosphingolipid-dependent biogenesis of clathrinindependent carriers. Nature Cell Biology 16, 595-606 (2014).

45. Renard, H.-F. et al. Endophilin-A2 functions in membrane scission in clathrin-independent endocytosis. Nature 517, 493-496 (2015).

46. Kononenko, N. L. et al. Clathrin/AP-2 mediate synaptic vesicle reformation from endosome-like vacuoles but are not essential for membrane retrieval at central synapses. Neuron 82, 981-988 (2014).

47. Watanabe, S. et al. Ultrafast endocytosis at mouse hippocampal synapses. Nature $\mathbf{5 0 4 , 2 4 2 - 2 4 7}$ (2013).

48. Lu, J. et al. Postsynaptic Positioning of Endocytic Zones and AMPA Receptor Cycling by Physical Coupling of Dynamin-3 to Homer. Neuron 55, 874-889 (2007).

49. Baschieri, F. et al. Frustrated endocytosis controls contractility-independent mechanotransduction at clathrin-coated structures. Nature Communications 9, 3825 (2018).

50. Morel, M., Bartolo, D., Galas, J.-C., Dahan, M. \& Studer, V. Microfluidic stickers for cell- and tissue-based assays in microchannels. Lab Chip 9, 1011-1013 (2009).

51. Courson, D. S. \& Rock, R. S. Fast Benchtop Fabrication of Laminar Flow Chambers for Advanced Microscopy Techniques. PLOS ONE 4, e6479 (2009). 